Finally, Dr Bowers expressed his concern about the length of time elapsed between conducting our study and the results being published. We appreciate the importance of avoiding such delay but would point out the following: (1) clinicians with numerous clinical duties need to plan the study, make the time for data analysis, writing and submitting papers, responding to reviewers, and wait after putting the paper in the queue of the articles accepted for publication until it is published; (2) the real question should be whether or not this delay has any impact on applicability of the study results. We feel that where the early intervention service model has already been adopted it is not too late for it to be reviewed and further developed. If, on the other hand, some areas have not yet developed their early intervention model, it is not at all late.

1 EL-Adl M, BurkeJ, Little K. Frist-episode psychosis: primary care experience and implications for service development. Psychiatr Bull 2009; 33: 165-8.

2 Shiers $D$, Lester $H$. Early intervention for firstepisode psychosis needs greater involvement of primary care professionals for its success. BMJ 2004; 328: 1451-2.

*Mamdouh EL-Adl Consultant Psychiatrist Northamptonshire Healthcare NHS Trust, Campbell House, Campbell Square, Northampton NN1 3EB, email: mamdouhkandil@doctors.org.uk, John Burke Consultant Psychiatrist, Northamptonshire Healthcare NHS Trust, Karen Little Clinical Governance and Professional Development Manager, Preston Primary Care Trust

doi: 10.1192/pb.33.8.314b

\section{Doctors in the house. Home visits for older people: a practical model outside Yorkshire}

There is a curious sentence in Negi et al's paper about psychiatric out-patient clinics for older adults. ${ }^{1}$ When they refer to Benbow's paper about community clinics, ${ }^{2}$ they state that 'this model has not been adopted either in rural or urban catchment areas'. No evidence is quoted for this sweeping statement.

Admittedly, in our fast moving National Health Service it is difficult to keep track of changes. In 1997 we investigated the work of old age psychiatrists. ${ }^{3}$ Every day of the week community clinics were reported by $20 \%$ or more of respondents (the corresponding figures for hospital out-patient clinics ranged between 17 and $28 \%$ ). Additional community activity was undertaken as domiciliary visits and new home visits. Domiciliary visits are welldefined: they incur additional payment and occur at the request of the general practitioner, normally in his or her company, to advise on diagnosis or treatment, where the patient cannot attend hospital on medical grounds. Home visits can involve follow-up or new assessments and are undertaken without additional remuneration as part of the doctor's working day.

We later reported a more in-depth analysis which found that community activity was greater among consultants working with colleagues in comparison with those who worked alone. ${ }^{4}$

Since then, Richardson \& Orrell have reported that home assessments are popular with patients, carers and professionals, going on to argue that they also provide more information. ${ }^{5}$ The College Faculty of Old Age Psychiatry seems to think community clinics are normal practice. ${ }^{6}$

In all the services we have worked in, home visits carried out during community clinics have been the norm - but then neither of us has worked in Yorkshire. Visits are efficient and cost-effective, with non-attendance rates consistently lower than $10 \%$ in our services, as well as providing the continuity of follow-up desired by patients, carers and colleagues in primary care and social services, and in line with the National Dementia Strategy. ${ }^{7}$ It is important that Negi et al set the record straight: in many good services for older people home visits are the reality.

1 Negi R, SeymourJ, Flemons C, Impey M, Thomas N, Witrylak R. Psychiatric out-patient clinics for older adults: highly regarded by users and carers, but irreplaceable? Psychiatr Bull 2009; 33: 127-9.

2 Benbow SM. The community clinic - its advantages and disadvantages. Int J Geriatr Psychiatry1990; 5: 119-21.

3 Jolley DJ, Benbow SM. The everyday work of geriatric psychiatrists. Int J Geriatr Psychiatry 1997; 12: 109-13.

4 Benbow SM, Jolley DJ. Gender, isolation, work patterns and stress amongst old age psychiatrists. Int J Geriatr Psychiatry 1999; 14: 719-25.

5 Richardson B, Orrell M. Home assessments in old age psychiatry. Advan PsychiatrTreat 2002; 8 : $59-65$

6 Faculty of Old Age Psychiatry. Raising the Standard. Specialist Services for Older People with Mental Illness. Royal College of Psychiatrists, 2006 (http://www.rcpsych.ac.uk/PDF/ RaisingtheStandardOAPwebsite.pdf).

7 Department of Health. Living Well with Dementia: A National Dementia Strategy. Department of Health, 2009.

Susan Mary Benbow Professor of Menta Health and Ageing, Centre for Ageing and Mental Health, Staffordshire University, Blackheath Lane, Stafford ST18 OAD, email: drsmbenbow@aol.com, David Jolley Consultant Psychiatrist, Pennine Care NHS Foundation Trust, and Honorary Reader, Manchester University Personal Social Services Research Unit

doi: $10.1192 / p b .33 .8 .315$

\section{Therapists' competence - maintenance matters too}

Davidson \& Scott left us in no doubt that therapist competencies matter in the delivery of psychological therapies. ${ }^{1}$ As a concept there has always been a degree of 'face validity' to this assertion, but it is the attention they devote to maintaining competence that is perhaps of most significance - and most concern - within psychiatry. In 2005, the Psychiatric Bulletin published the results of a survey of psychiatrists who had received training to diploma level at one of Scotland's recognised cognitive-behavioural therapy (CBT) courses. ${ }^{2}$ The results clearly established that access to personal supervision and for some also opportunities in continuing professional development were poor. Nevertheless, there was optimism that with the advent of job planning, consultant psychiatrists could spell out and negotiate for the time needed to undertake this, so as to ensure that these specific skills are not wasted. Indeed, Whitfield concludes that 'planners should think carefully about how to harness and hold on to psychiatrists with these (CBT) skills if future diversity in psychological skills training is to be assured'. ${ }^{2}$

For CBT at least, the assessment of the competencies required to deliver effective therapy has been aided by the publication of a self-assessment tool by the British Association for Behavioural and Cognitive Psychotherapies (www.babcp.com/ members-/a-self-assessment-tool-of-cbtcompetences-/), in response to the 2007 Department of Health publication, ${ }^{3}$ and the Royal College of Psychiatrists has outlined the competencies required for training in psychotherapy in general. Not knowing why, how or what to do is no longer an issue.

Unfortunately, in 2009 consultants face increasing pressure from employers to replace supporting professional activity time with direct clinical care time, the assumption being that this will bring better value for money for the National Health Service. Jobs with as few as one supporting professional activity are being advertised which in our view is inadequate to allow consultant psychiatrists to be involved in teaching and training as well as maintaining their own continuing professional development. This would be regarded as completely unacceptable by others involved in delivering psychological therapies, for example clinical psychologists.

It seems highly likely that increased direct clinical care time by consultants will come at the expense of robust supervision arrangements for them and for the supervision that they can supply. This makes it likely that improved access to psychological therapies, at least as delivered by psychiatrists, will not bring 